Volume 45, Supplementary Issue (S1), p. 305-313, October 2017

CFaculty of Veterinary Medicine, Zagazig University, 44511, Egypt

DOI: $10.21608 / z v j z .2017 .29253$.

\title{
Virological and Immunological Diagnosis of Bovine Viral Diarrhea Virus in Rabbits
}

\author{
Sherine M. Zaghlal ${ }^{1,2 *}$, Ali A.A. Salama ${ }^{1}$, Mohammed EL-Bakry A. Ismail ${ }^{1}$, Gamelat K. Farag ${ }^{1}$ \\ Manal B. Mahmoud ${ }^{2}$, and Ahmed Abd El-Samie H. Ali ${ }^{1}$ \\ ${ }^{1}$ Virology Department, Faculty of Veterinary Medicine, Zagazig University, 44511, Egypt \\ ${ }^{2}$ Animal Reproduction Research Institute, Giza, Egypt.
}

\section{Abstract}

Bovine viral diarrhea (BVD) is a viral infectious disease of cattle. Other animals may act as reservoirs of BVDV; Rabbits are wide range in many countries, frequently existing close to farm animals. Recent studies revealed that BVDV propagated in rabbits through different routes of infections. Thus, New Zealand White rabbits were infected with two biotypes of BVDV (NADL and 890) through different routes (intravenous, nasal and oral). No clinical signs appeared on the infected rabbits. On the other hand, the lymphoid organs (GALF) of ileum of rabbits of BVDV infected groups and sacrificed at day five post infections showed depletion in the population of lymphocytes in the center of some lymphoid follicles. By RT-PCR some buffy coat samples and most organ samples in all exposed groups were virus positive at day five post infection, however samples of mock-infected control group remained negative. Antibodies development was observed in all groups infected animals, while in mock-infected control group, there was not production of antibodies. Innate immunity was detected by assessment of lysozyme and nitric oxide concentrations. There was an increase in lysozyme and nitric oxide concentrations in BVDV exposed groups when compared with mock infected group after day three as a defense mechanism of the host against the virus. Conclusion, these results indicates that rabbits are susceptible to infection by BVDV biotypes without clinical signs and lesions.

Keywords: BVDV, Rabbit, GALF, PCR, Lysozyme, Nitric oxide.

\section{Introduction}

BVDV is a member of genus Pest viruses in the family Flaviviridae. BVDV is ss+ sense RNA virus with a genome of $12.5 \mathrm{~kb}$ [1]. There are two major genotypes BVDV I and BVDV II. Each genotype is classified into two biotypes; cytopathic and non cytopathic according to the cytopathic effect on cell culture [2]. It gives rise to significant economic losses in both dairy and beef cattle [3]. The main source of BVDV infection is the persistently infected (PI) animals that shed virus in the environment, but other infected species can also transmit it by direct and indirect contact [4]. Recent researches of BVDV founded that a range of animals such as horses, dogs, mouse and rabbit were also inoculated with the virus for determining the host range. It is founded that the virus could be propagated in rabbit; Baker et al. [5] reported that calves infected with spleen homogenate of rabbits which had been infected with BVDV five days earlier, the clinical signs were typically to transient BVDV infection [6]. Other recently, it was recorded that rabbits were infected by BVDV, not just intravenous but also by other routes of infection [7].
Therefore, the present study aimed to get more information about experimental infection of rabbits with two biotypes of BVDV.

\section{Material and Methods}

\section{Experimental design}

Thirty -nine male White, New Zealand rabbits, 12 weeks old were used in the experiment. They were purchased from Faculty of Agriculture, Zagazig University, Egypt. Animals were randomly classified into seven groups (six infected groups $\mathrm{n}=6$ and one mock exposed $n=3$ ). Each group was infected with the virus in the dose of $1 \mathrm{~mL}$ of virus (106TCID50) [7]. Animals were exposed to cytopathic (CP) strain (NADL) or non cytopathic (NCP) strain (890). Rabbits were grouped as following: Group 1 (I/V group): It was exposed to CP BVDV by intravenous via ear vein. Group 2 (O group): It was exposed to $\mathrm{CP}$ BVDV orally. Group 3 (N group): It was exposed to CP BVDV intranasal. Group 4 (I/V group): It was exposed to NCP BVDV by intravenous via ear vein. Group 5 (O group): It was exposed to NCP BVDV orally. Group 6 ( $\mathrm{N}$ group): It was exposed to NCP BVDV

*Corresponding author email: (dr_chrry54@yahoo.com), Virology Department, Faculty of Veterinary 305 Medicine, Zagazig University, 44511, Egypt. 
intranasal. Group 7 (Mock-exposed): Negative control. Samples of blood were taken from ear vein without anticoagulant at day 0 , before exposure, and on days 3, 5, 7, 14, 21 and 28 after exposure. They were used for separation of serum for ELISA, nitric oxide, lysosyme assays. At days 5, 14 and 28 post-infection, two infected animals from each group and one mock-exposed were scarified. The whole blood samples were collected with anticoagulant for separation of buffy coat. The other blood samples were collected with an anticoagulant then centrifuged at $2000 \mathrm{rpm}$ for 10 minutes. Plasma was collected and then sterile distilled water was added to the samples for $50 \mathrm{sec}$ RBCS' hemolysis' then double volume of PBS was added. The tubes were centrifuged at $2000 \mathrm{rpm}$ for 10 minutes and repeat that for 3 to 4 times for obtaining a clear buffy coat. Whole blood samples were collected without an anticoagulant then were centrifuged at $2000 \mathrm{rpm}$ for 10 minutes. Sera were collected in Eppendorf tubes and frozen.

\section{The virus}

The viruses used in this study were international NADL and 890 . The viruses were kindly supplied by Dr. Ahmed Ali, Professor and Head of Virology Department, Faculty of Veterinary Medicine, Zagazig University, Egypt. The titer of each virus is expressed as TCID50/ml; NADL 5x10 and $89016 \times 10^{6}$.

\section{Real time PCR for detection of BVDV in buffy coat and organ samples}

Extraction of RNA from buffy coat and organ samples was performed using a viral RNA mini kit (QIAGEN, USA) according to the manufacturer's instructions.

\section{Serological identification of BVDV antibodies using indirect ELISA:}

Antibodies in serum samples of groups $0,3,5,7,14,21$ and 28 days were detected by ELISA using ELISA plates coated with BVDV NADL or BVDV 890 according to Chénard et al. [9].

\section{Assessment of serum lysozyme concentration}

Lysozymes activity in the serum was assayed at the fore mentioned periods of ELISA according to Schultz, [10].

Assessment of nitric oxide concentration: Nitric oxide level in the serum sample was assessed at the same periods of ELISA according to Rajaraman et al. [11].

\section{Histopathological examination}

The rabbits were sacrificed on 5, 14 and 28 days and subjected to histopathological examination. Specimen from succulus rotundus (ileum) of all exposed rabbits among different groups were collected and fixed in neutral buffered formalin paraffin blocks were prepared and 5 microns sections were stained with hematoxline and eosin and examined microscopically Bancroft et al., [12].

Table 1: Detection of BVDV in buffy coat and organs of experimentally infected rabbits at 5 dpi using Real time RT-PCR

\begin{tabular}{llll}
\hline Group & \multicolumn{2}{c}{ Samples } \\
\cline { 2 - 4 } & \multicolumn{1}{c}{ Buffy coat } & Spleen & Ileum \\
Group 1 & Positive & Positive & Positive \\
Group 2 & Negative & Negative & Negative \\
Group 3 & Negative & Positive & Negative \\
Group 4 & Positive & Positive & Negative \\
Group 5 & Negative & Positive & Positive \\
Group 6 & Negative & Negative & Negative \\
Group 7 & Negative & Negative \\
\hline
\end{tabular}

Group 1: It was exposed to CP BVDV by intravenous via ear vein.

Group 2: It was exposed to CP BVDV orally.

Group 3: It was exposed to CP BVDV intranasal.

Group 4: It was exposed to nCP BVDV by intravenous via ear vein.

Group 5: It was exposed to nCP BVDV orally.

Group 6: It was exposed to nCP BVDV intranasal.

Group 7: Negative control. 


\section{Results}

Detection of BVDV in Buffy coat and organs of experimentally infected rabbits using Real time RT-PCR

Following exposure to BVDV, Buffy coats samples were BVDV positive in IV/CP and IV/NCP exposed groups, while other groups were negative. The spleen samples from $\mathrm{IV} / \mathrm{CP}, \mathrm{O} / \mathrm{CP}, \mathrm{IV} / \mathrm{NCP}, \mathrm{O} / \mathrm{NCP}$ and IN/NCP exposed groups were positive, while spleen of IN/CP exposed rabbits was negative. The ileum samples of IV/CP and O/NCP exposed groups were the only positive groups. Buffy coats, spleen and ileum samples from mock exposed rabbits were negative (Table 1).

$B V D V$ antibodies detection in serum of experimentally infected rabbits using ELISA

Detection of BVDV antibodies in serum of experimentally infected rabbits using ELISA plates coated with BVDV NADL. The development of antibodies of all BVDV exposed animals of IV/CP group increased at three day post infection, although the peak was at day 14. In O/CP exposed group the antibody response increased after day five and reached the peak at day 21. In IN/CP group, the level of the antibody response also increased after day 3 and reached the peak at day 14, but it was slightly decreased compared to the intravenous infected groups. While in all groups infected with NCP virus (IV/NCP, $\mathrm{O} / \mathrm{NCP}, \quad \mathrm{IN} / \mathrm{NCP})$, the antibody response increased after day three and persist for day 28 . While the mock group remained negative (Table 2). Detection of BVDV antibodies in serum of experimentally infected rabbits using ELISA plates coated with BVDV 890, The development of antibodies of all BVDV exposed animals increased after day five post infection in all cytopathic infected groups, while the peak was at day 28 in IV/NCP and at day 21 in both $\mathrm{O} / \mathrm{NCP}$ and IN/NCP groups, but slightly decreased compared to that of IV/NCP, while the mock exposed rabbit remained negative.

Table 2: Detection of BVDV antibodies* in serum of experimentally infected rabbits using ELISA plates coated with BVDV NADL.

\begin{tabular}{lccccccc}
\hline Group & \multicolumn{7}{c}{ Days post infection } \\
\cline { 2 - 8 } & $\mathbf{0}$ & $\mathbf{3}$ & $\mathbf{5}$ & $\mathbf{7}$ & $\mathbf{1 4}$ & $\mathbf{2 1}$ & $\mathbf{2 8}$ \\
\hline Group 1 & $0.192 \pm 0.028$ & $0.664 \pm 0.051$ & $0.776 \pm 0.043$ & $0.952 \pm 0.093$ & $1.478 \pm 0.386$ & $0.916 \pm 0.075$ & $0.898 \pm 0.071$ \\
Group 2 & $0.174 \pm 0.035$ & $0.22 \pm 0.012$ & $0.4 \pm 0.058$ & $0.502 \pm 0.054$ & $0.586 \pm 0.050$ & $0.68 \pm 0.056$ & $0.586 \pm 0.066$ \\
Group 3 & $0.202 \pm 0.026$ & $0.49 \pm 0.056$ & $0.664 \pm 0.051$ & $0.776 \pm 0.043$ & $0.952 \pm 0.093$ & $0.91 \pm 0.076$ & $0.888 \pm 0.111$ \\
Group 4 & $0.184 \pm 0.046$ & $0.384 \pm 0.015$ & $0.606 \pm 0.051$ & $0.852 \pm 0.028$ & $1.1 \pm 0.154$ & $1.076 \pm 0.141$ & $1.002 \pm 0.119$ \\
Group 5 & $0.13 \pm 0.033$ & $0.302 \pm 0.019$ & $0.418 \pm 0.059$ & $0.546 \pm 0.043$ & $0.652 \pm 0.034$ & $0.772 \pm 0.023$ & $0.78 \pm 0.015$ \\
Group 6 & $0.134 \pm 0.032$ & $0.324 \pm 0.023$ & $0.49 \pm 0.015$ & $0.622 \pm 0.052$ & $0.73 \pm 0.041$ & $0.824 \pm 0.032$ & $0.914 \pm 0.043$ \\
Group 7 & $0.0046 \pm 0.037$ & $0.04 \pm 0.033$ & $0.0512 \pm 0.032$ & $0.0286 \pm 0.023$ & $0.0054 \pm 0.032$ & $0.0062 \pm 0.044$ & $0.0446 \pm 0.013$ \\
\hline
\end{tabular}

* Results are represented by mean value of S/P ratios \pm standard deviation. Groups 1, 2, 3: BVDV cytopathic infected groups by IV, O, IN respectively. Groups 4, 5, 6: BVDV non cytopathic infected groups by IV, O, IN respectively. Group 7: mock infected group.

\section{Assessment of Serum Lysozyme Concentration}

There was an increase in lysozyme concentration in infected groups when compared with mock infected group. In BVDV cytopathic infected groups, the I/V infected one showed high concentration of lysozyme with a peak at day 7 post infection, In the group $\mathrm{O} / \mathrm{CP}$, the level of the lysozyme concentration also increased after day 5 , while the group exposed to BVDV by $\mathrm{IN} / \mathrm{CP}$, the level of the lysozyme concentration reached the peak at day 14, but it was slightly decreased compared to the IV group. I/V/NCP infected group showed high concentration of lysozyme with a peak at day 14 post infection. In $\mathrm{O} / \mathrm{NCP}$ and IN/NCP exposed groups, the level of the lysozyme concentration reached the peak at day 7 post infection. While the mock exposed rabbit remained negative (Table $3)$. 


\section{Assessment of nitric oxide concentration}

There was an increase in nitric oxide concentration in BVDV exposed groups when compared with mock infected group (Table 4).

Histopathological analysis of rabbits experimentally infected with two biotypes of $\boldsymbol{B V D V}$

Neither CP and NCP BVDV infected rabbits showed any clinical signs or postmortem lesions. The main recorded lesion in all scarified rabbits was observed in Succulus rotundus and represented by moderate depletion in the population of lymphocytes from the center of the lymphoid follicles in GALF in all BVDV infected groups, while the Succulus rotundus of mockinfected control group, had normal histological structures (Figure 1).

Table 3: Assessment of serum lysozyme* concentration in rabbits experimentally infected with BVDV strains and mock infected rabbits.

\begin{tabular}{cccccccc}
\hline \multirow{2}{*}{ Group } & \multicolumn{7}{c}{ Days post infection } \\
\cline { 2 - 8 } & $\mathbf{0}$ & $\mathbf{3}$ & $\mathbf{5}$ & $\mathbf{7}$ & $\mathbf{1 4}$ & $\mathbf{2 1}$ & $\mathbf{2 8}$ \\
\hline Group 1 & $18.92 \pm 3.4$ & $66.18 \pm 2.9$ & $76.36 \pm 4.1$ & $176.908 \pm 17.7$ & $123.18 \pm 8.3$ & $110.42 \pm 6.9$ & $95.14 \pm 3.9$ \\
Group 2 & $19.58 \pm 3.1$ & $61.92 \pm 2.1$ & $69.2 \pm 2.4$ & $156.4 \pm 5.4$ & $141.24 \pm 4.0$ & $93.74 \pm 3.8$ & $88.24 \pm 4.6$ \\
Group 3 & $19.38 \pm 3.0$ & $53.58 \pm 1.6$ & $59.98 \pm 2.5$ & $129.74 \pm 10.8$ & $146.925 \pm 4.0$ & $74.96 \pm 6.4$ & $59.26 \pm 3.2$ \\
Group 4 & $20.86 \pm 2.0$ & $71.46 \pm 1.9$ & $82.46 \pm 2.7$ & $119.26 \pm 13.9$ & $149.04 \pm 9.0$ & $95.12 \pm 13.2$ & $91.94 \pm 7.1$ \\
Group 5 & $21.54 \pm 2.7$ & $59.2 \pm 1.1$ & $77.28 \pm 1.5$ & $158.66 \pm 12.5$ & $127.8 \pm 18.0$ & $84.88 \pm 6.2$ & $78.74 \pm 2.6$ \\
Group 6 & $21.9 \pm 4.4$ & $63.98 \pm 2.1$ & $74.22 \pm 2.5$ & $125.78 \pm 10.2$ & $97.96 \pm 5.9$ & $91.54 \pm 5.2$ & $86.44 \pm 3.8$ \\
Group 7 & $19.58 \pm 3.1$ & $22.5 \pm 3.7$ & $20.92 \pm 5.7$ & $19.94 \pm 3.2$ & $20.4 \pm 5.1$ & $21.64 \pm 3.4$ & $21.54 \pm 2.7$ \\
\hline
\end{tabular}

* Results are represented by mean value of lysozyme concentration $(\mu \mathrm{M}) \pm$ the standard deviation. Groups 1, 2, 3: BVDV cytopathic infected groups by IV, O, IN respectively. Groups 4, 5, 6: BVDV non cytopathic infected groups by IV, O, IN respectively. Group 7: mock infected group.

Table 4: Assessment of nitric oxide* concentration in rabbits experimentally infected with BVDV and mock infected rabbits.

\begin{tabular}{|cccccccc}
\hline \multirow{2}{*}{ Group } & \multicolumn{7}{c}{ Days post infection } \\
\cline { 2 - 8 } & 0 & 3 & 5 & 7 & 14 & 21 & 28 \\
\hline Group 1 & $4.2 \pm 0.47$ & $9.16 \pm 1.0$ & $15.26 \pm 0.91$ & $21.18 \pm 2.3$ & $37.28 \pm 5.0$ & $25.78 \pm 4.30$ & $13.66 \pm 2.2$ \\
Group 2 & $4.926 \pm 1.6$ & $6.64 \pm 0.70$ & $7.36 \pm 1.0$ & $17.68 \pm 3.0$ & $28 \pm 2.6$ & $16.8 \pm 2.6$ & $7.68 \pm 1.7$ \\
Group 3 & $4.52 \pm 0.77$ & $10.42 \pm 2.3$ & $29.48 \pm 2.2$ & $19.92 \pm 1.5$ & $15.68 \pm 0.77$ & $10.72 \pm 1.7$ & $9.02 \pm 1.4$ \\
Group 4 & $5.108 \pm 1.5$ & $12.66 \pm 0.85$ & $14.76 \pm 0.86$ & $19.04 \pm 2.8$ & $23.6 \pm 3.1$ & $40.3 \pm 1.8$ & $21.82 \pm 3.0$ \\
Group 5 & $4.72 \pm 0.438178$ & $7.28 \pm 0.653452$ & $10.04 \pm 0.64$ & $11.18 \pm 0.96$ & $13.78 \pm 1.7$ & $15.74 \pm 1.5$ & $13.78 \pm 2.0$ \\
Group 6 & $4.9 \pm 0.689202$ & $12.78 \pm 0.549545$ & $19.8 \pm 1.1$ & $26.2 \pm 3.8$ & $37.32 \pm 3.1$ & $27.12 \pm 3.9$ & $15.96 \pm 1.7$ \\
Group 7 & $4.54 \pm 0.684105$ & $4.78 \pm 0.356371$ & $4.68 \pm 0.60$ & $4.44 \pm 0.56$ & $4.24 \pm 0.81$ & $4.58 \pm 0.96$ & $4.12 \pm 1.3$ \\
\hline
\end{tabular}

* Results are represented by mean value of nitric oxide concentration $(\mu \mathrm{M}) \pm$ the standard deviation. Groups 1, 2, 3: BVDV cytopathic infected groups by IV, O, IN respectively. Groups 4, 5, 6: BVDV non cytopathic infected groups by IV, O, IN respectively. Group 7: mock infected group.

\section{Discussion}

The bovine viral diarrhea virus is typically a pathogen of cattle worldwide but it can infect other hosts. Some studies have suggested that rabbit can be infected naturally by BVDV [13]. The latest experimental study has established that rabbits can take infection with BVDV by several natural routes. Consequently, there are indications that rabbits could be a natural wildlife reservoir for BVDV [14]. Thus, it was reported that rabbits could be host for natural infection [7]. Therefore, in this study, rabbits were infected with two biotypes of BVDV by different routes of infection and detection of virus and development of specific antibody responses were measured. Infection of the rabbits with BVDV through $\mathrm{I} / \mathrm{V}$ inoculation was used as a positive control because this had been reported before as a successful route of BVDV infection of rabbits [13], while nasal and oral routes of virus were represented a more natural routes of virus entry. The viruses used in this study were international NADL and 890. 
There were no any clinical signs on the infected rabbits nor increase in body temperature after infection, this is agreed with previous studies [5,7]. This seems remarkable in observation of the virus propagation and depleted GALF seen in some rabbits. BVDV RNA was detected by real time RT-PCR in samples of buffy coat isolated from rabbits in the intravenous $\mathrm{CP}$ and $\mathrm{NCP}$ groups at day five post infection, but not detected in other groups. This is suggesting the low loading of BVDV during viraemia and primarily cellassociated. This is similar to the transient infection of cattle where occurrence of viraemia at a similar time, post infection to that which we observed for these rabbits [15]. Remarkably, viraemia in cattle is not easily detected in all cases and shedding of virus is very limited [16]. However, RNA of BVDV was detected in a number of organs pat day five samples of spleen of all BVDV exposed rabbits in the IV, IN and $\mathrm{O}$ groups which were positive but not detected in intranasal cytopathic group and mock exposed group. As the viraemia appears to be associated primarily with leukocytes [6], frequent detection of BVDV in the spleen is not amazing and explains why intravenous virus infection using homogenate of spleen was successfully used in previous experiments [5, 7]. Detection of BVDV RNA in the GALF of Succulus rotundus part of the ileum of IV/CP and $\mathrm{O} / \mathrm{NCP}$ was recorded. Succulus rotundus in the rabbit is corresponding to the Peyer's patches in cattle. That is similar as in PI cattle, where the virus is typically detected in the Peyer's patches that show severe lymphoid depletion subsequent the onset of mucosal disease [17]. Detection of viraemia at day five followed by increase of antibody response in all BVDV exposed rabbits of IV, $\mathrm{O}$ and IN groups by day five but not in any pre-exposure samples nor the mock exposed animals, although we cannot accurately detect the seroconversion time point in the rabbits, the antibody onset increased between days three and five and that was similar to that occurs in cattle where it takes between 2 and 14 days post infection for an animal to show clinical signs or an elevated antibody response against the virus [18]. In addition, cellular immunity is essential for protection against re-infection in cattle [19]. The innate immunity was detected through measurement of lysozyme and nitric oxide concentrations at different days post infection. Lysozyme is an enzyme that hydrolyses the cell wall of some microorganisms and thereby kills the organism. Lysozyme is a common constituent of biological tissues and secretions. Lysozyme is also present in cytoplasmic granules of the macrophages and the polymorphonuclear neutrophils and monocytes. Lysozyme assay is an enzymatic assay that used to determine the amount of enzymatic activity present in a given sample [20].

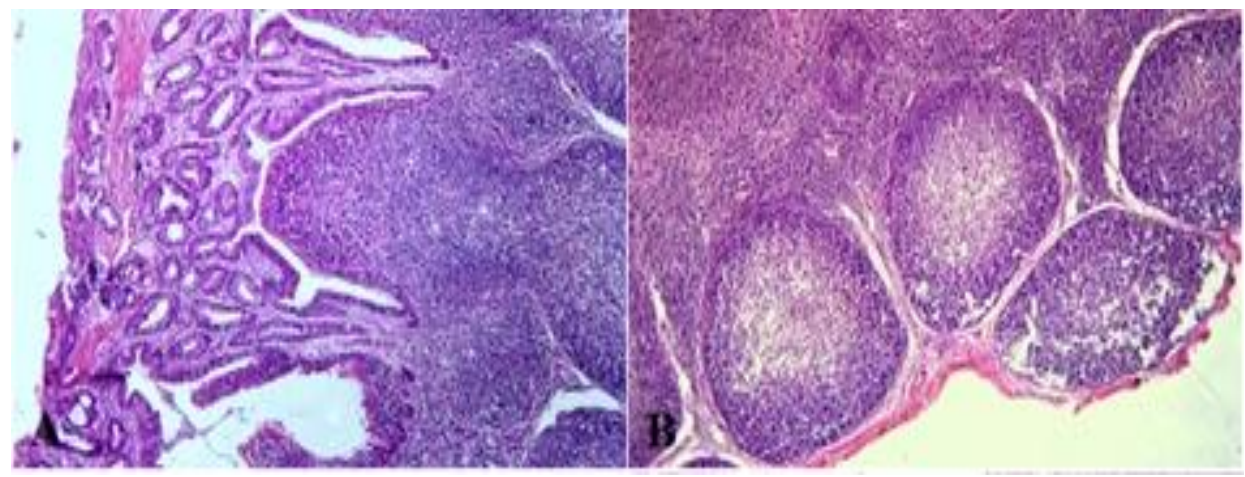

Figure 1: Hisopathological findings of Succulus rotundus of rabbits infected with BVDV (NADL) scarified on 5 days post infection and control mock-infected rabbits. A) mock-infected control rabbit, showing normal histological structures represented by normal population of lymphocytes in the lymphoid follicles. H\&E X100. B) Rabbits infected with $\mathrm{CP} / \mathrm{BVDV}$ orally, showing moderate depletion in the population of lymphocytes in some lymphoid follicles. H\&E X100. 
Lysozyme diffuses through the agarose gel containing a suspension of Micrococcus lysodeikticus as the substrate. A clear zone ring of lysis develops on the agarose gel. The assessment of lysozyme concentration was performed in all groups at different days post infection. There was increase in lysozyme concentration in BVDV exposed groups when compared with mock infected group, this is in accordance with previously reported results [21], who recorded that the lysozyme has an important role in the defense of the host against micro-organisms, and the findings suggest that lysozyme may reach its target by several routes. In BVDV exposed $\mathrm{O} / \mathrm{CP}$ and $\mathrm{O} / \mathrm{NCP}$ groups, the level of the lysozyme concentration increased after day 3 and reached a high peak at day 7 , this is may be due to that in oral route, the virus replicate in lymphoid organs of ileum that contains large numbers of macrophage that responsible for synthesis of lysozyme, this is agreed with McClelland and Furth [21], who found in his study that lysozyme synthesis has been demonstrated in the mucosa of the respiratory and gastrointestinal tracts, and lymphoid organs of mice. Nitric oxide (NO) is main intracellular signaling molecule formed by a variety of cell types including immune cells. Under physiological levels, NO has an important role in different processes for example, the host defensive response against pathogens [22]. It is recognized that many chronic and acute inflammatory diseases are associated with increased production of NO in inflammatory cells like macrophages [23]. Nitrite is the stable oxidation product of nitric oxide, its concentration correlates with the amount of nitric oxide in the supernatant. The amount of nitrite was determined by mixing the supernatant with the colorless Griess reagent forming purple complex. The degree of the developed color was measured spectrophotometrically using ELISA reader at $570 \mathrm{~nm}$. In this study, the assessment of nitric oxide concentration was performed in all groups at different days post infection. There was increase in concentration of nitric oxide in BVDV exposed groups when compared with mock infected group. It showed significant increase at day 5 and 7 post infection, while in non-cytopathic BVDV exposed group the increase was at day 5. This means that production of nitric oxide increased after exposure to the BVD virus. This agreed with MacMicking et al. [24], where it was founded that the interface between the adaptive and innate immune systems lays the high output nitric oxide synthase (NOS2) which is responsible for high output of nitric oxide production [25]. NOS2 has been documented in macrophages from human, horse, cow, goat, mouse, and chicken. Human NOS2 is most readily observed in monocytes or macrophages from patients with infectious or inflammatory diseases. Sustained production of NO endows macrophages with cytostatic or cytotoxic activity against viruses, bacteria, fungi, protozoa, helminthes, and tumor cells; also Nitric oxide is endogenously released in the airways by nitric oxide synthase [26]. The increase of lysozyme and nitric oxide concentrations in rabbits after exposure to BVDV, these results were in accordance with Khoudair et al. [27], they noticed that the activity of Nitric oxide and Lysozyme in cattle and buffaloes infected with brucellosis or/with tuberculosis alone was higher than those with mixed infection as a result of stress action of Brucella and Mycobacterium microorganisms on macrophage. Finally, the third approach of this study was to investigate histological changes occurred in rabbits experimentally infected with BVDV biotypes. The main recorded lesion was observed in Succulus rotundus with presence of moderate depletion in the population from center of lymphoid follicles of GALF in infected groups with all BVDV biotypes (Figure 2), while the mock infected control group, had normal histological structure with normal population of lymphocytes. These findings were in accordance with Bachofen et al. [7]. The fore mentioned lesion also detected in transient infection of cattle with BVDV, where depletion of the Peyer's patches was ranged from mild to moderate [28].

\section{Conclusion}

The results of the present study evidenced that rabbits are susceptible to infection by BVDV biotypes without appearance of any clinical signs or disease. Virus and antibodies detection suggested that rabbits can be a host for BVDV. Virus propagation was detected after intravenous, intranasal and oral infection. 
Different route of infection led to an antiBVDV immune response, as measured by ELISA. While some aspects of infection seem to be similar to infection in cattle, such as the time course of antibody development and the targeting of GALT organs, others are clearly different, such as lack of clinical signs.

\section{Conflict of interest}

The authors declare no conflict of interest.

\section{References}

[1]Collett, M.S. (1992): Molecular genetics of pestiviruses. Comparative Immunology and Infectious Diseases, 15: 145.

[2]Ridpath, J.F.; Bolin; S.R. and Dubovi, E.J. (1994): Segregation of bovine viral diarrhea viruses into genotypes. Virology, 205: 66-74.

[3]Campbell, J. R., (2004): Effect of bovine diarrhea virus in the feedlot. Vet. Clin. North. Am. Food Anim. Pract. 20(1):3950.

[4]Fulton, R .W.; Briggs, R. E.; Ridpath, J. F.; Saliki, J. T.; Confer, A. W.; Payton, M. E.; Duff, G. C.; Step, D. L. and Walker, D. A., (2005): Transmission of bovine viral diarrhea virus $1 \mathrm{~b}$ to susceptible and vaccinated calves by exposure to persistently infected calves. Can J Vet Res 69 (3):161-169.

[5] Baker, J.A.; York, C.J.; Gillespie, J.H. and Mitchell, G.B. (1954). Virus diarrhea in cattle. Am J Vet Res. ;15:525-531.

[6] Fernelius, A.L.; Lambert, G.; and Packer, R.A. ( 1969): Bovine viral diarrhea virushost cell interactions: adaptation, propagation, modification, and detection of virus in rabbits. Am $J$ Vet Res.;30:1541-1550.

[7] Bachofen, C.; Grant, D.M.; Willoughby, K.; Zadoks, R.N.; Dagleish, P.M. and Russell, G.C. (2014): Experimental infection of rabbits with bovine viral diarrhoea virus by a natural route of exposure. Veterinary Research, 45: 34.

[8] González, L.; Anderson, I.; Deane, D.; Summers, C. and Buxton, D. (2001): Detection of immune system cells in paraffin wax-embedded ovine tissues. J Comp Pathol, 125:41-47.

[9]Chénard, G.; Miedema, K.; Moonen, P.; Schrijver, R. S. and Dekker, A. (2003): A solid-phase blocking ELISA for detection of type $\mathrm{O}$ foot-and-mouth disease virus antibodies suitable for mass serology. Journal of Virological Methods, 107: 8998.

[10]Schultz, L. A., (1987): Lysozyme. In: Methods in clinical Chemistry. A. J. Pesce and L. A. Kaplan, (Eds). St. Louis: Mosby, pp 742- 746.

[11]Rajaraman, V.; Nonnecke, B.J.; Franklin, S.T.; HammellD, C. and Horst, R.L (1998): "Effect of vitamins A and Eon nitric oxide production byblood mononuclear leukocytes from neonatal calves fedmilk replacer." J Dairy Sci., 81:3278-3285

[12]Bancroft, J.D.; Stevens, A. and Turner, D.R. (1996): Theory and practice of Histological. Technique.4th ed., Churchill Livingstone., New York, London, San Francisco, Tokyo.

[13]Frölich, K. and Streich, W.J. (1998): Serologic evidence of bovine viral diarrhea virus in free-ranging rabbits from Germany. J Wildl Dis. ;34:173-178. doi: 10.7589/0090-3558-34.1.173.

[14]Grant, D. M.; Dagleish, M. P.; Bachofen, C.; Boag, B.; Deane, D.; Percival, A.; Zadoks, R. N. and Russell, G. C. (2015): Assessment of the rabbit as a wildlife reservoir of bovine viral diarrhea virus serological analysis and generation of trans-placentally infected offspring. Front Microbiol

doi: 10.3389/fmicb.2015.01000.

[15]Muller, D.; Arquint, A.; Schaller, P.; Heegaard, P.M.; Hilbe, M.; Albini, S.; Abril, C.; Tobler, K.; Ehrensperger, F. ; Peterhans, E. and et al., (2004): Innate immune responses of calves during transient infection with a noncytopathic strain of bovine viral diarrhea virus. Clinical and Diagnostic Laboratory Immunology 11, 302-312.

[16] Nickell, J.S.; White, B.J.; Larson, R.L.; Renter, D.G. and Sanderson, M.W. 
(2011): A simulation model to quantify the value of implementing whole-herd Bovine viral diarrhea virus testing strategies in beef cow-calf herds. J Vet Diagn Invest 23:194-205.

[17]Shin, T. , Acland, H. (2001): Tissue distribution of bovine viral diarrhea virus antigens in persistently infected cattle. $\mathbf{J}$ Vet Sci.;2(2):81-4.

[18]Stevenson,W. T. ( 2012): Bovine Viral Diarrhea in Dairy and Beef Cattle. California Polytechnic State University, San Luis Obispo.

[19]Ridpath, J.F. (2013): Immunology of BVDV vaccines. Biologicals. Jan; 41(1):14-9.

[20]Yoshimura, K.; Toibana, A. and Nakahama, K. (1988): Human lysozyme: sequencing of a cDNA, and expression and secretion by Saccharomyces cerevisiae". Biochem. Biophys. Res. Commun. 150 (2): 794-801.

[21]McClelland D. B. and Furth R. van (1975): In vitro synthesis of lysozyme by human and mouse tissues and leucocytes. Immunology. Jun; 28(6): 1099-1114.

[22]Bogdan, C.; Röllinghoff, M.and Diefenba ch, A. (2000): The role of nitric oxide in innate immunity. Immunol Rev. 173:1726.

[23] Chin, M. P., Schauer, D. B., Deen, W. M. (2008): Prediction of nitric oxide concentrations in colonic crypts during inflammation. Nitric Oxide. 19:266-275.

[24]Macmicking J. ; Xie Q. W. and Nathan C.(1997): Nitric oxide and macrophage function. Annu Rev Immunol. ;15:323-50.

[25]Kuncewicz, T.; Balakrishnan, P.; Snuggs, M. B. and Kone, B. C. (2001): Specific association of nitric oxide synthase- 2 with $\mathrm{Rac}$ isoforms in activated murine macrophages. Am J Physiol Renal Physiol.;281(2):F326-36.

[26] Ricciardolo, .F. (2003): Multiple roles of nitric oxide in the airways Thorax.; 58(2): 175-182.

[27]Khoudair, R.M; Ibrahim, E.M; Saker, G.G and Hafez, M.A. (2009): Clinicodiagnostic and pathological studies on cattle and buffaloes suffering from brucellosis and tuberculosis in Kafr El Sheikh Governorate. Egypt. J. Comp. Path. \& Clinic. Path. Vol. 22 No. 1; 148 174.

[28]Pedrera, M.; Sa'nchez-Cordon, P. J.; Romero -Trevejo, J. L., Risalde, M. A.; Greiser-Wilke, I., $\mathrm{Nu}^{\prime} \mathrm{n}$ ez, A. and Gomez-Villamandos, J. C. (2009): Morphological changes and viral distribution in the ileum of colostrumdeprived calves inoculated with noncytopathic bovine viral diarrhea virus genotype-1. J Comp Pathol 141, 52-62. 


$$
\begin{aligned}
& \text { الملخص العربى } \\
& \text { التثخيص الفيروسي والمناعى لفيروس الاسهال البقرى الحموى فى الارانب }
\end{aligned}
$$

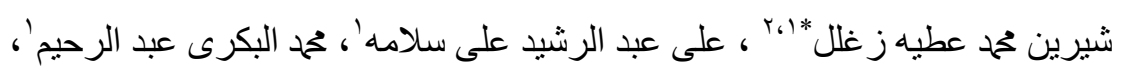

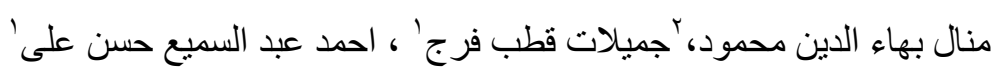

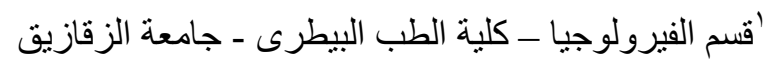

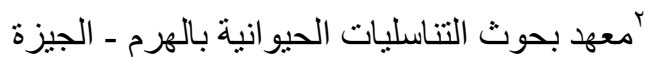

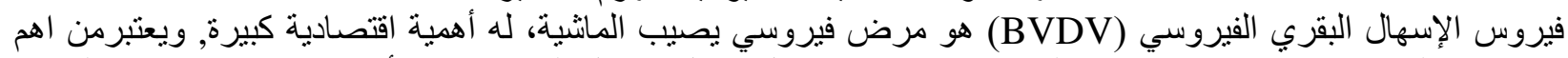

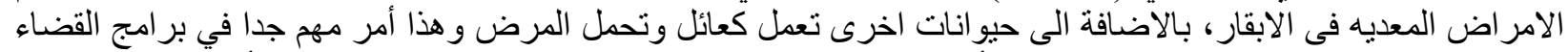

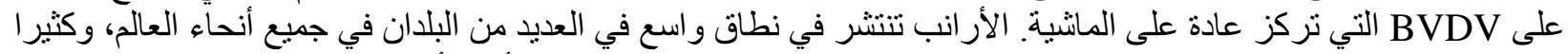

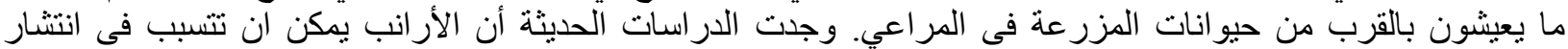

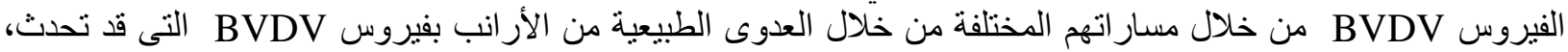

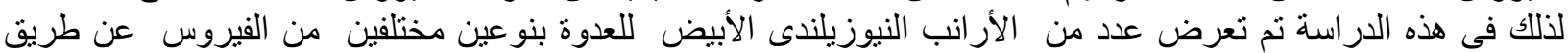

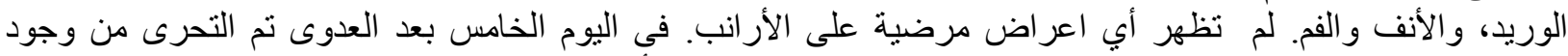

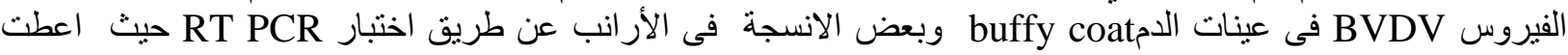

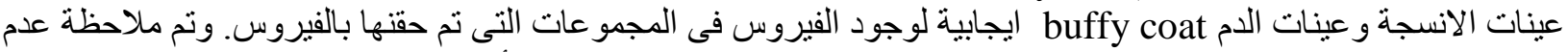

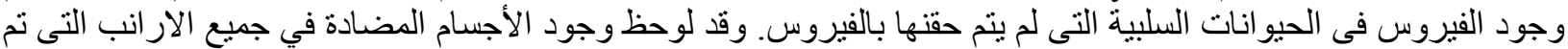

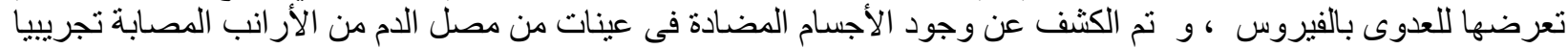

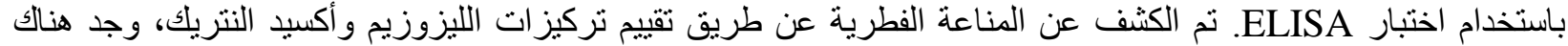

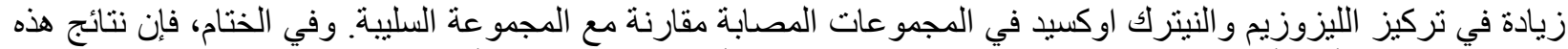

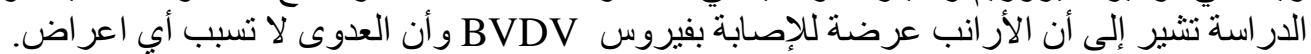

